\title{
High miR-122 expression promotes malignant phenotypes in ccRCC by targeting occludin
}

\author{
KENTARO JINGUSHI $^{1}$, YURI KASHIWAGI ${ }^{1}$, YUKO UEDA $^{1}$, KAORI KITAE ${ }^{1}$, HIROAKI HASE $^{1}$, \\ WATARU NAKATA ${ }^{2}$, KAZUTOSHI FUJTA ${ }^{2}$, MOTOHIDE UEMURA ${ }^{2}$, \\ NORIO NONOMURA ${ }^{2}$ and KAZUTAKE TSUJIKAWA ${ }^{1}$ \\ ${ }^{1}$ Laboratory of Molecular and Cellular Physiology, Graduate School of Pharmaceutical Sciences, Osaka University; \\ ${ }^{2}$ Department of Urology, Graduate School of Medicine, Osaka University, Suita, Osaka 565-0871, Japan
}

Received February 13, 2017; Accepted March 29, 2017

DOI: $10.3892 /$ ijo.2017.4016

\begin{abstract}
Renal cell carcinoma (RCC) is the most common neoplasm of the adult kidney, and clear cell RCC (ccRCC) represents its most common histological subtype. Although several studies have reported high expression of miR-122 in ccRCC, its physiological role remains unclear. To clarify the role of miR-122 in ccRCC, we compared miR-122 expression levels in non-cancerous tissue and ccRCC. Significant upregulation of miR-122 was observed in ccRCC specimens. Moreover, ccRCC patients with high miR-122 expression showed poor progression-free survival compared to those with low miR-122 expression. Overexpression of miR-122 using an miRNA mimic promoted proliferation, migration, and invasion activities of ccRCC cells. miR-122 directly targets occludin, a known component of tight junctions. Occludin knockdown promoted the cell migration activity but not proliferation or invasion activities of ccRCC cells. In human clinical specimens, miR-122 expression inversely correlated with occludin protein expression. These findings show that miR-122 is an oncomiR in ccRCC.
\end{abstract}

\section{Introduction}

Renal cell carcinoma (RCC) represents the leading cause of death due to urological malignancies (1) and clear cell renal cell carcinoma (ccRCC) is the most common histological subtype of RCC. Despite improvements in available treatments, the

Correspondence to: Dr Kentaro Jingushi, Laboratory of Molecular and Cellular Physiology, Graduate School of Pharmaceutical Sciences, Osaka University, 1-6 Yamadaoka, Suita, Osaka 565-0871, Japan E-mail: jingushi-kk@phs.osaka-u.ac.jp

Abbreviations: miR-122, microRNA-122; ccRCC, clear cell renal cell carcinoma; oncomiR, onco-microRNA

Key words: miR-122, clear cell renal cell carcinoma, occludin prognosis remains poor for locally advanced and metastatic ccRCC (2). Therefore, understanding the molecular basis of ccRCC is crucial to design a novel therapeutic drug that will improve survival rate.

MicroRNAs (miRNAs) are non-coding RNAs that regulate gene expression, mainly at the translational level (3). Anomalous changes in miRNA expression have been shown to be associated with several human cancers including ccRCC (4-6). Various studies have reported the miRNA profile in ccRCC specimens using microarray and RNA sequencing technologies (7-11). Although altered miRNA expression has been reported in ccRCC, the mechanisms through which miRNAs contribute to ccRCC pathogenesis remain poorly understood.

MicroRNA-122 (miR-122), a known tumour suppressor in hepatocellular carcinoma (HCC), functions by targeting oncogenes such as cyclin G1 (12), CDK4 (13), and AKT3 (14). However, several studies have also shown that miR-122 is highly expressed in ccRCC $(10,15,16)$, suggesting that miR-122 functions as an onco-microRNA (oncomiR) in renal cancer $(17,18)$. Whilst the physiological role of miR-122 in cancer appears dependent on cancer types, the precise mechanism of miR-122 on ccRCC progression is largely unknown.

Tight junctions govern the permeability of epithelial and endothelial cells and are the most topical structure of these cell types (19-21). It is thought that the interaction with and penetration of the endothelium by cancer cells is a key step in the formation of metastasis (22-24). Occludin, a component of tight junctions, possesses four transmembrane domains, two extracellular loops and two intracellular domains (25). Numerous studies have emphasized the important role of occludin in the assembly and maintenance of tight junctions (26-28). Moreover, several studies suggest that occludin also plays a tumour suppressor role. Raf-1 disrupts tight junctions through the downregulation of occludin, and overexpression of occludin suppresses Raf-1-induced tumour growth in rat salivary gland epithelial cells (29). Occludin has also been shown to regulate oncogenic properties in several cancers (30-34). In ccRCC, loss of function of von HippelLindau (VHL), a tumour suppressor gene, is known to downregulate the expression of occludin and lead to disruption of tight junction assembly (35). 
Herein, we showed that highly expressed miR-122 correlated with low progression-free survival compared to low miR-122 expression in ccRCC clinical specimens. We further demonstrated that miR-122 promoted malignant phenotypes partially via targeting occludin in ccRCC cells. Finally we showed that occludin was significantly downregulated in ccRCC specimens compared to normal kidney tissues, and this correlated with the expression levels of miR-122. Our findings identify that miR-122 is as a potent regulator of malignant phenotypes and functions as an oncomiR in ccRCC, leading to a novel therapeutic strategy for treatment of ccRCC.

\section{Materials and methods}

Chemicals and antibodies. miRIDIAN miRNA hairpin inhibitor negative control, miRIDIAN miRNA mimic negative control, miRIDIAN hairpin inhibitor or miRIDIAN miRNA mimic for human hsa-miR-122 (MIMAT0000421) were purchased from Thermo Scientific Dharmacon (Waltham, MA, USA). The miRIDIAN hairpin inhibitors and mimics were used at a concentration of $50 \mathrm{nM}$. Polyclonal anti-occludin and monoclonal anti- $\beta$-tubulin antibodies were purchased from Sigma (St. Louis, MO, USA). Polyclonal Anti-ACTIVE p38 $\left(\mathrm{Thr}^{180} / \mathrm{Tyr}^{182}\right)$ and Anti-ACTIVE JNK1/2 $\left(\mathrm{Thr}^{183} / \mathrm{Tyr}^{185}\right)$ antibodies were purchased from Promega (Madison, WI, USA). Monoclonal anti-phospho-Erk1/2 $\left(\mathrm{Thr}^{202} / \mathrm{Tyr}^{204}\right)$, anti-Erk1/2, and anti-p38 antibodies were purchased from Cell Signaling Technology (Beverly, MA, USA). Monoclonal anti-JNK1/2 antibody was purchased from BD Transduction Laboratories (San Jose, CA, USA).

Clinical specimens. ccRCC specimens were obtained from patients while they underwent primary curative resection at the Osaka University Medical Hospital, Japan. Tumour-associated normal renal tissue was also obtained from a subset of these patients when possible. Prior written and informed consent was obtained from each patient, and the study was approved by the ethics review board of the Osaka University Medical Hospital and the methods were carried out in accordance with the approved guidelines.

Quantitative real-time PCR. Following excision, tissue samples were immediately immersed in RNAlater (Qiagen, Valencia, CA, USA) and stored at $-20^{\circ} \mathrm{C}$ until RNA extraction. miRNAs were purified using the miRNeasy mini kit (Qiagen). Real-time PCR analysis was conducted to validate miR-122 expression in ccRCC using 80 tumour samples and 10 adjacent normal renal samples (for Fig. 1B-D) and another distinct 122 tumour tissue samples (for Fig. 1E and F) using the Mir-X miRNA first-strand synthesis kit (Takara, Shiga, Japan). Thermal cycling conditions included an initial step at $98^{\circ} \mathrm{C}$ for $30 \mathrm{sec}$, and 40 cycles at $95^{\circ} \mathrm{C}$ for $2 \mathrm{sec}$ and $66^{\circ} \mathrm{C}$ for $5 \mathrm{sec}$ using an miR-122 specific primer (5'-tggagtgtgacaatggtgtttg-3'), and $98^{\circ} \mathrm{C}$ for $30 \mathrm{sec}$, and 40 cycles at $95^{\circ} \mathrm{C}$ for $2 \mathrm{sec}$ and at $63^{\circ} \mathrm{C}$ for $5 \mathrm{sec}$ by using an U6 snRNA primer (Takara). Clinical and pathological data related to the clinical samples are presented in Table I.

Cell culture. Three human ccRCC cell lines (Caki-1, Caki-2 and, ACHN), obtained from the American Type Culture
Table I. Clinical and pathological data related to the clinical samples.

\begin{tabular}{lcc}
\hline Characteristics & $\begin{array}{c}\text { Validation cohort } \\
\text { for miR-122 } \\
\text { expression }\end{array}$ & $\begin{array}{c}\text { For the } \\
\text { PFS } \\
\text { analysis }\end{array}$ \\
\hline Age (year) & 62.6 & 63.8 \\
Mean & $35-86$ & $34-82$ \\
Range & & \\
Gender & 58 & 38 \\
Male & 31 & 83 \\
Female & 1 & 1 \\
Unknown & & \\
Pathologic stage & 10 & 0 \\
Normal & 11 & 56 \\
pT1a & 69 & 65 \\
pT1b & 0 & 1 \\
Unknown & & \\
Pathologic grade & 23 & 47 \\
G1 & 52 & 2 \\
G2 & 5 & 1 \\
G3 & 0 & 10 \\
Unknown & & \\
Lymphatic invasion & 74 & \\
- & 6 & \\
+ & &
\end{tabular}

Collection (ATCC), were cultured in RPMI-1640 medium (Wako, Osaka, Japan) supplemented with $10 \%$ fetal bovine serum, $100 \mathrm{U} / \mathrm{ml}$ penicillin $\mathrm{G}$, and $0.1 \mu \mathrm{g} / \mathrm{ml}$ streptomycin.

Western blotting. Protein samples were separated by sodium dodecyl sulphate (SDS)-polyacrylamide gel electrophoresis (PAGE) on a 7.5-15\% SDS-polyacrylamide gel and then transferred to a polyvinylidene difluoride membrane using the Bio-Rad semi-dry transfer system (1 h, $12 \mathrm{~V}$ ). Immunoreactive proteins reacting with the antibodies described above were visualized by treatment with a detection reagent (ECL Prime western blotting detection reagent; GE Healthcare, Lafayette, CO, USA). Densitometric analysis was performed using NIH ImageJ software.

Luciferase reporter assay. A pmirGLO dual-luciferase miRNA target expression vector was used for the 3'-UTR luciferase reporter assay (Promega). The following oligonucleotides were used for the evaluation of efficacy of the miR-122 hairpin inhibitor on occludin 3'-UTR: 5'-CTA GCG GCC GCT AGT TCA ACT GGG CTG AAC ACT CCA G-3' and 5'-TCG ACT GGA GTG TTC AGC CCA GTT GAA CTA GCG GCC GCT AGA GCT-3'. Luciferase activity was determined using a luminometer (Turner Biosystems 20/20 n luminometer, Promega).

Wound healing assay. Cell migration was examined by wound healing assay. In brief, Caki-2 cells transfected with 
A
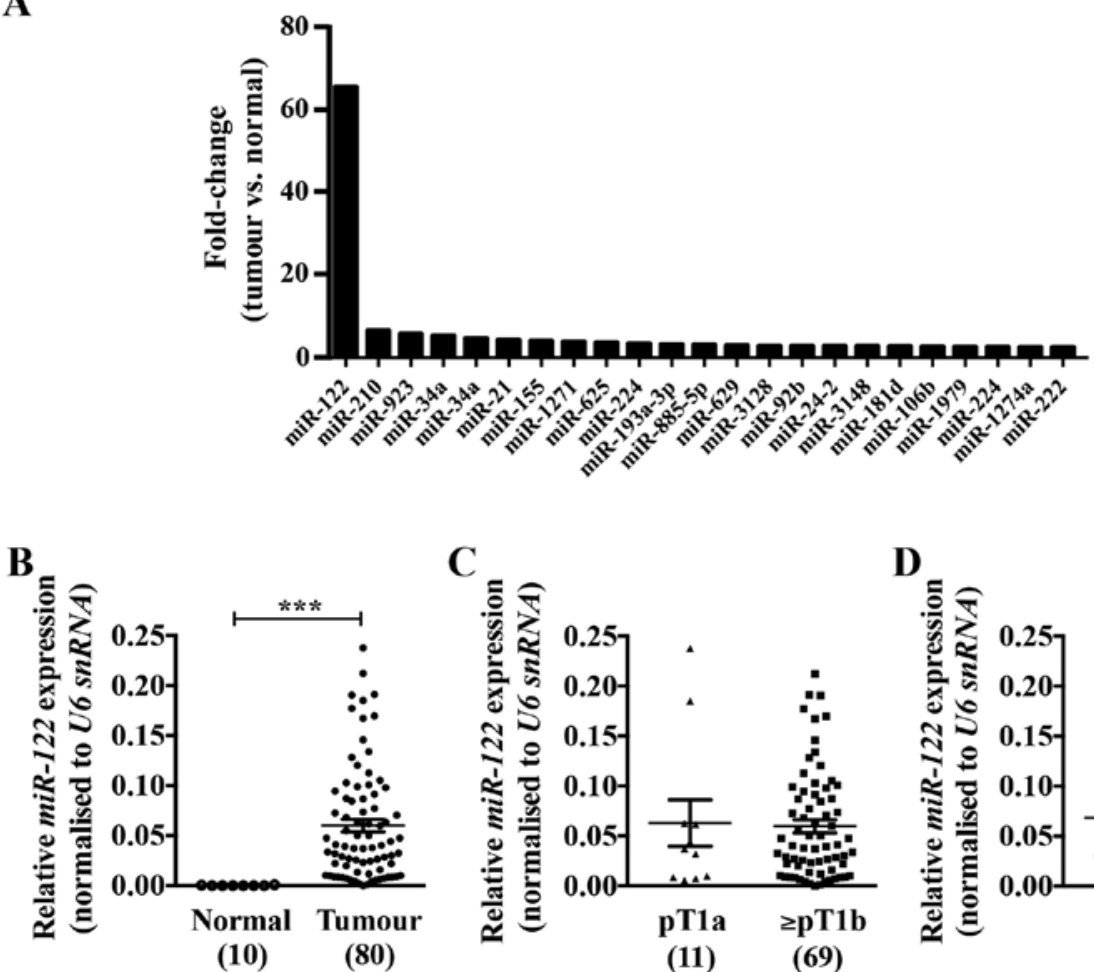

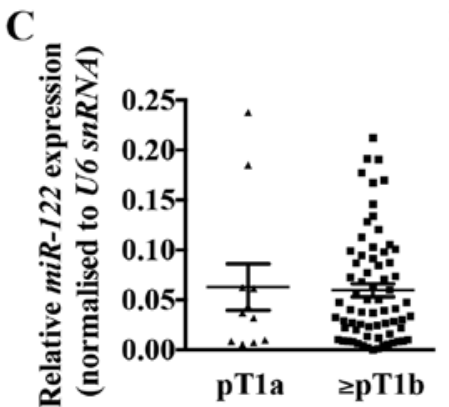

(11)
D

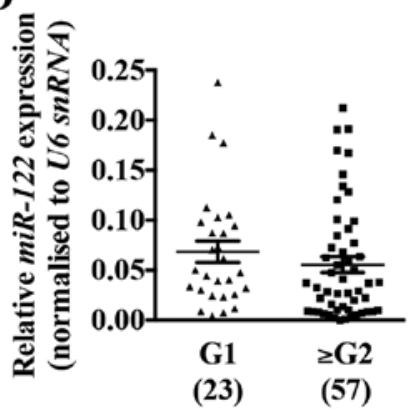

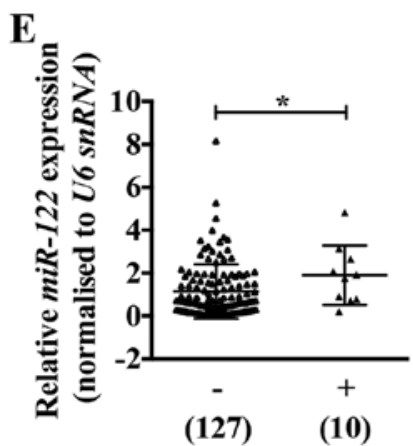

F

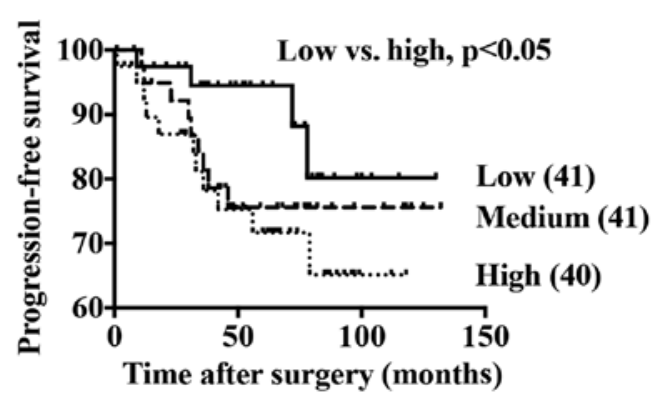

Figure 1. miR-122 expression in ccRCC tissues. (A) miRNA microarray analysis showed upregulated expression of these miRNAs (fold-change $>2$, p $<0.05$ normal adjacent kidney vs. ccRCC) in ccRCC specimens. The expression of miR-122 was compared in normal and tumour tissues (B), pathological stages (C), and pathological grades (D) in ccRCC clinical specimens. Number of the samples is given in parentheses. (E) miR-122 expression was compared between ccRCC tissues with (+) and without (-) lymphovascular cancer cell invasion. Number of the samples is given in parentheses. * $\mathrm{p}<0.05$ vs. non-invaded ccRCC tissue. (F) Progression-free survival. ccRCC tissue samples were divided into three groups according to miR-122 expression (low: 41 samples; middle: 41 samples; and high: 40 samples). ${ }^{*} \mathrm{p}<0.05$ low vs. high. ${ }^{* * *} \mathrm{p}<0.001$.

the miRIDIAN hairpin inhibitor or the negative control inhibitor, and ACHN cells transfected with the miRIDIAN microRNA mimic or the negative control mimic were seeded in a 24 -well plate (Caki-2 cells: $2.0 \times 10^{4}$ cells/well, ACHN cells: $4.0 \times 10^{4}$ cells/well) and incubated for $72 \mathrm{~h}$. A wound was created in a monolayer of approximately $90 \%$ confluent Caki-2 or ACHN cells using a sterile $1 \mathrm{ml}$ pipette tip. Cell migration pictures were recorded at 0 and $12 \mathrm{~h}$ after wound creation using an Olympus IX71 fluorescence microscope.

Water-soluble tetrazolium salt-1 (WST-1) cell proliferation assay. Cell proliferation was examined by WST-1 assay. Caki- 2 cells transfected with the miRIDIAN hairpin inhibitor or the negative control inhibitor, and ACHN cells transfected with the miRIDIAN miRNA mimic or the negative control mimic were seeded in a 96 -well plate $\left(0.3 \times 10^{4}\right.$ cells/well $)$ and incubated for $72 \mathrm{~h}$. After incubation for $2 \mathrm{~h}$ with the WST-1 reagent (Dojindo, Osaka, Japan) at $37^{\circ} \mathrm{C}$ and $5 \% \mathrm{CO}_{2}$, the optical density was read at a wavelength of $450 / 630 \mathrm{~nm}$ $(\mathrm{Ex} / \mathrm{Em})$.

Soft agar colony formation assay. Caki-2 or ACHN cells were seeded at $1.0 \times 10^{4}$ cells/well in 6-well plates in RPMI-1640 medium (supplemented with $10 \%$ FBS and $0.3 \%$ agarose with $0.4 \%$ agarose underlay). Dishes were incubated at $37^{\circ} \mathrm{C}$ and $5 \%$ $\mathrm{CO}_{2}$. After 14 days, colonies were stained with crystal violet (Wako) and counted.

Cell invasion assay. The BioCoat tumour invasion system (Corning Inc., Corning, NY, USA) was used to perform the cell invasion assay. Caki-2 cells transfected with the miRIDIAN hairpin inhibitor or the negative control inhibitor were seeded in a 96 -well plate $\left(3 \times 10^{4}\right.$ cells/well). Following incubation for $12 \mathrm{~h}$, the cells were labelled with calcein AM $(4 \mu \mathrm{g} / \mathrm{ml}$, 
A

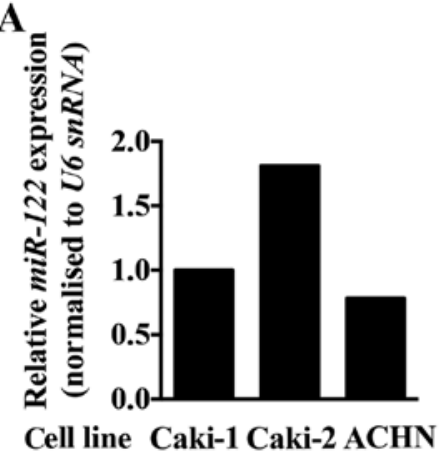

B

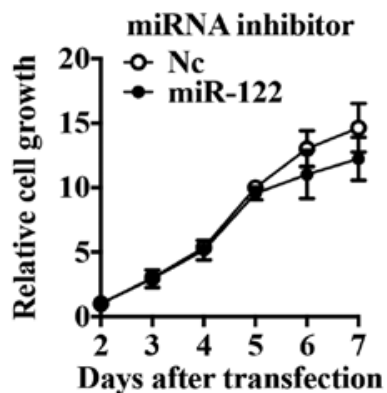

C

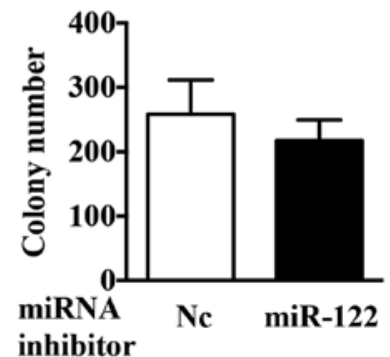

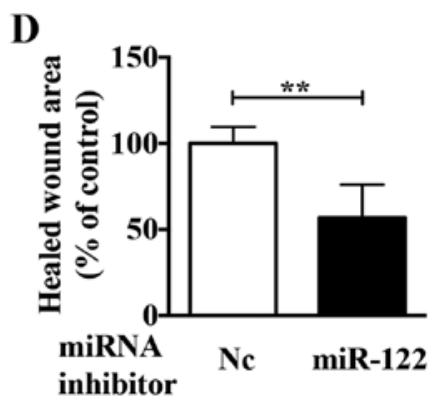

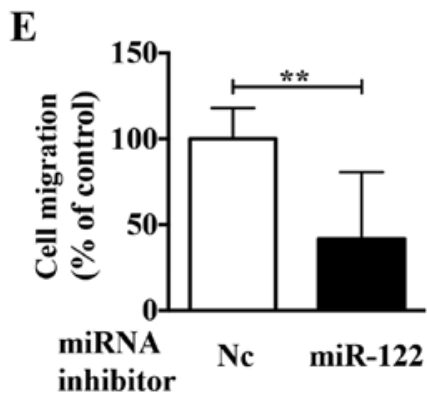

Figure 2. miR-122 inhibitor downregulates the migration and invasion activities in Caki-2 cells. (A) Expression of miR-122 in three ccRCC cell lines was examined by quantitative real-time PCR. Duplicated result is shown. (B) Caki-2 cells transfected with the miR-122 inhibitor, or the negative control miRNA inhibitor, for $24 \mathrm{~h}$ were reseed in a 96-well plate $\left(0.3 \times 10^{3}\right.$ cells/well), incubated for the indicated times and examined by WST-1 assay. Values are mean \pm SD of three independent experiments. (C-E) Caki-2 cells were transfected with the miR-122 inhibitor, or the negative control miRNA inhibitor, for $72 \mathrm{~h}$. (C) The transfected cell suspension was added to soft agar plates and cultured for 2 weeks, and then the colony number was counted. The results are expressed as mean \pm SD of three independent experiments. (D) Cell migration was measured $12 \mathrm{~h}$ after a wound was created by scraping. Representative results of cell mobility in the wound-healing assay are shown. The results are expressed as mean \pm SD of five independent experiments. ** $\mathrm{p}<0.01$ vs. the control inhibitor. (E) The transfected cell suspension was added to the upper chamber of a matrigel-coated CIM-plate. The lower chamber was filled with medium and cultured for $24 \mathrm{~h}$ in the $\mathrm{xCELLigence} \mathrm{system.} \mathrm{Values} \mathrm{expressed} \mathrm{as} \mathrm{cell} \mathrm{index} \mathrm{are} \mathrm{mean} \pm \mathrm{SD}$ of seven experiments. ${ }^{* *} \mathrm{p}<0.01$ vs. the control inhibitor.

Takara), and the fluorescence of the invaded cells was read at a wavelength of 494/517 $\mathrm{nm}(\mathrm{Ex} / \mathrm{Em})$.

Fluorescence microscopy. Cells plated on coverslips were washed with phosphate-buffered saline (PBS). The cells were fixed and permeabilized in $4 \%$ formaldehyde for $15 \mathrm{~min}$ at room temperature and then washed twice with PBS. After blocking with $2 \%$ bovine serum albumin in PBS for $1 \mathrm{~h}$, the coverslips were incubated with the anti-occludin antibody $(1: 500)$ at $4^{\circ} \mathrm{C}$. The coverslips were washed twice with PBS and incubated with the fluorochrome-conjugated secondary antibody for $1 \mathrm{~h}$ at room temperature. The cells were then examined under the fluorescence microscope, Bio-Zero (Keyence, Osaka, Japan).

Immunohistochemistry. The expression of occludin was determined by immunohistochemical staining of paraffinembedded tissues of ccRCC samples with the highest and lowest levels of miR-122 expression samples (10 samples of each). Formalin-fixed paraffin-embedded sections $(5 \mu \mathrm{m}$ in thickness) were deparaffinized and rehydrated. After the slides were steamed for $20 \mathrm{~min}$ in $10 \mathrm{mM}$ citrate buffer ( $\mathrm{pH} \mathrm{6.0)}$ ) for antigen retrieval, endogenous peroxidase was blocked using $3 \% \mathrm{H}_{2} \mathrm{O}_{2}$. Immunohistochemical staining for occludin was performed using anti-occludin (1:500) and the EnVision ${ }^{+}$ Detection System (Dako, Santa Clara, CA, USA) was used according to the manufacturer's instructions. Primary antibodies were incubated overnight at $4{ }^{\circ} \mathrm{C}$ and counterstained with hematoxylin. The levels of occludin staining were classified into four groups according to the staining intensity of the positive cells (staining score, 0-3; Fig. 5F) and Quick score was calculated as follows; Quick score = (percentage of occludin positive cells) x (staining score). For each ccRCC sample, three points were calculated.

Transendothelial electrical resistance (TEER) measurement. ACHN cells transfected with occludin siRNAs or miR-122 mimic for $48 \mathrm{~h}$ were reseeded $\left(1.0 \times 10^{5}\right.$ cells/well $)$ on a $0.4 \mu \mathrm{m}$ pore size 24-well cell culture insert (Thermo Scientific Dharmacon) and incubated for 1 day. TEER was measured using a Millicell ${ }^{\circledR}$ ERS-2 voltohmmeter (Millipore, Billerica, MA, USA). TEER was calculated as follows: (sample well $\Omega$ - empty well $\Omega)$ x (cultured area $\left.\mathrm{cm}^{2}\right)=\operatorname{TEER}\left(\Omega \mathrm{cm}^{2}\right)$.

Statistics. The results are expressed as the mean \pm standard deviation (SD). Differences between the values were statistically analysed using the Student's t-test or one-way analysis of variance (ANOVA) with Bonferroni post-hoc tests. Correlations between the values were analysed using Pearson correlation analysis (GraphPad Prism 6.0, GraphPad software, San Diego, CA, USA). A P-value of $<0.05$ was considered statistically significant.

\section{Results}

High miR-122 expression correlates with poor progressionfree survival in ccRCC. In our previous microarray analysis 
A

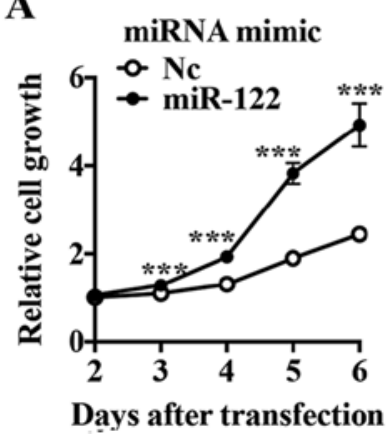

B

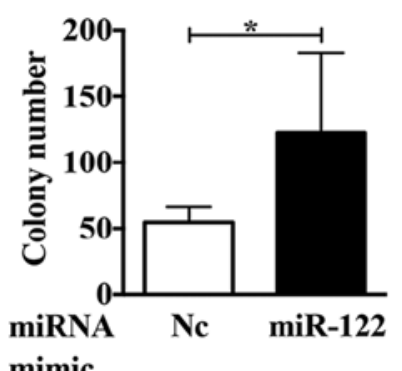

C

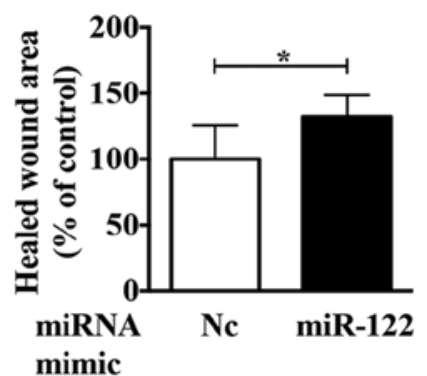

D

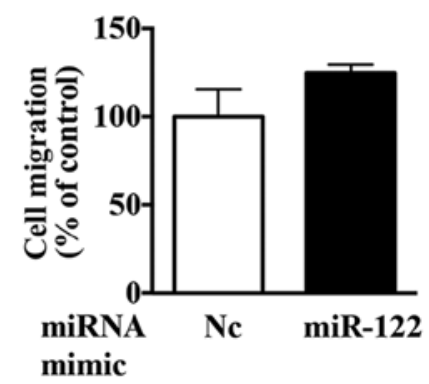

Figure 3. miR-122 mimic upregulates growth and migration activities in ACHN cells. (A) ACHN cells transfected with the miR-122 mimic, or the negative control miRNA mimic, for $24 \mathrm{~h}$ were reseed in a 96 -well plate $\left(0.3 \times 10^{3}\right.$ cells/well), incubated for the indicated times and examined by WST-1 assay. Values are means \pm SD of six independent experiments. ${ }^{* * *}$ p $<0.001$ vs. the control mimic. (B-D) ACHN cells were transfected with the miR-122 mimic, or the negative control miRNA mimic, for $72 \mathrm{~h}$. (B) The transfected cell suspension was added to soft agar plates and cultured for 2 weeks, and then the colony number was counted. The results are expressed as mean \pm SD of three independent experiments. ${ }^{*} \mathrm{p}<0.05$ vs. the control mimic. (C) Cell migration was measured $12 \mathrm{~h}$ after a wound was created by scraping. The results are expressed as mean \pm SD of six independent experiments. * p $<0.05$ vs. control mimic. (D) The transfected cell suspension was added to the upper chamber of matrigel-coated Transwell membrane inserts, and the lower chamber was filled with the medium and then cultured for $12 \mathrm{~h}$. Fluorescence derived from invasive cells was measured. Values are mean \pm SD of three independent experiments.

identifying unique miRNA expression signatures (GEO accession number: GSE55138) (8), aberrantly high expression of miR-122 was detected in ccRCC tissues compared with adjacent normal renal tissues (Fig. 1A). To confirm the expression of miR-122 in ccRCC specimens we performed real-time PCR analysis. Although there was no correlation with pathological stages or grades (Fig. 1C and D), the expression of miR-122 was approximately 300-fold higher in the ccRCC tissues compared to the adjacent normal renal tissues (Fig. 1B) and was significantly high in ccRCC tissues accompanied by lymphatic invasion compared with those without lymphatic invasion (Fig. 1E). Noteworthy, ccRCC patients with high miR-122 expression had significantly poorer progression-free survival compared with those with low miR-122 expression (Fig. 1F).

miR-122 inhibitor reduced migration and invasion activities of Caki-2 cells. To investigate the role of miR-122 in ccRCC, we first compared the expression levels of miR-122 in three ccRCC cell lines (Caki-1, Caki-2, and ACHN, Fig. 2A). Since the expression of miR-122 was highest in Caki-2 cells, we first analysed the function of miR-122 using Caki- 2 cells. To investigate the function of miR-122, we examined the effect of a miR-122 inhibitor on growth, migration, and invasion in Caki- 2 cells. Although the miR-122 inhibitor had no significant effect on the cell growth (Fig. 2B and C), migration and invasion activities were significantly reduced in Caki-2 cells (Fig. 2D and E). Of the cell lines examined, ACHN cells had the lowest miR-122 expression. Using a miR-122 mimic in ACHN cells, we observed upregulated proliferation (Fig. 3A and B), migration (Fig. 3C), and invasion activities (Fig. 3D). These results suggest that miR-122 is involved in regulating the expression of crucial molecule/s in ccRCC cells.

miR-122 regulates occludin expression in ccRCC cells. We used target prediction programs (miRbase, TargetScan, and miRanda) to identify the potential miR-122 target in ccRCC cells. We then focused on occludin as a potential target, because it is a component of tight junctions and functions as a tumour suppressor in several cancers $(30,31)$. TargetScan predicts that the 3'-untranslated region (UTR) of occludin mRNA contains a complementary site for the seed region of miR-122 (Fig. 4A). To confirm whether or not occludin was a direct target of miR-122, the miR-122 inhibitor and a luciferase reporter plasmid containing the predicted miR-122 binding site (within the 3'-UTR of the human occludin gene) were co-transfection into Caki-2 cells. Luciferase activity confirmed that the reporter construct was working appropriately (Fig. 4B). The luciferase activity in cells co-transfected with the miR-122 inhibitor increased significantly compared to those co-transfected with the negative control inhibitor. Conversely, compared to the negative control mimic, the miR-122 mimic significantly decreased the luciferase activity (Fig. 4C). Moreover, the miR-122 inhibitor upregulated the expression of occludin protein in Caki-2 cells (Fig. 4D), and the miR-122 mimic reduced occludin protein expression in ACHN cells (Fig. 4E). These results indicated that occludin is a direct target of miR-122 in ccRCC cells.

Occludin knockdown upregulates cell migration activity in ACHN cells. To examine whether the malignant phenotypes upregulated by the miR-122 mimic in ccRCC cells were due to the decrease in occludin expression, we performed occludin knockdown experiments in ACHN cells (Fig. 5A and B). Occludin knockdown upregulated the migration activity of ACHN cells. The motility of ACHN cells was upregulated by occludin knockdown. Transepithelial electrical resistance (TEER) analysis showed that miR-122 mimic and occludin knockdown downregulated the TEER in the cells (Fig. 5C and D). TEER is a quantitative method to measure the integrity of tight junctions in cultured cells. These results suggest that miR-122 might upregulate the permeability of tight junctions via occludin reduction, leading to an increase in the motility of ACHN cells.

miR-122 expression and occludin protein expression have an inverse correlation in ccRCC specimens. The miR-122 inhibitor upregulated the expression of occludin at the cell-cell adhesive 
A

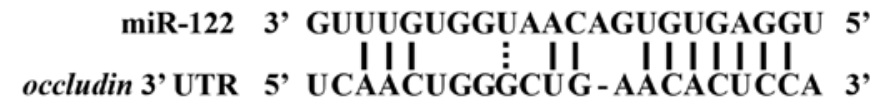

B

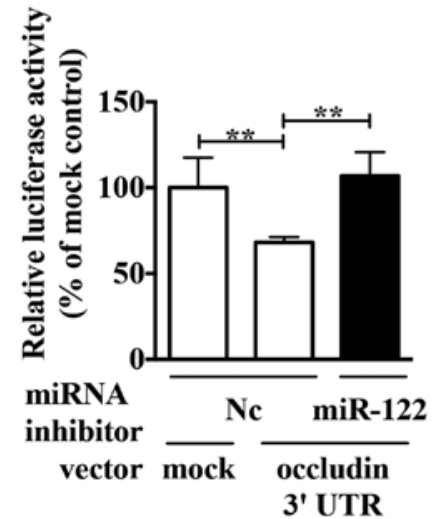

D
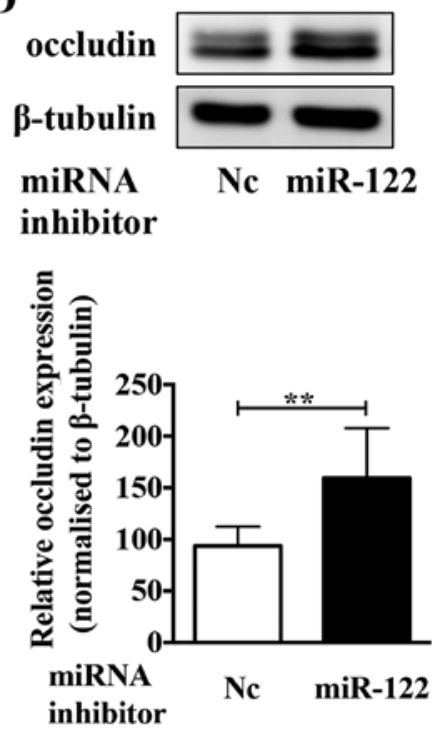

C

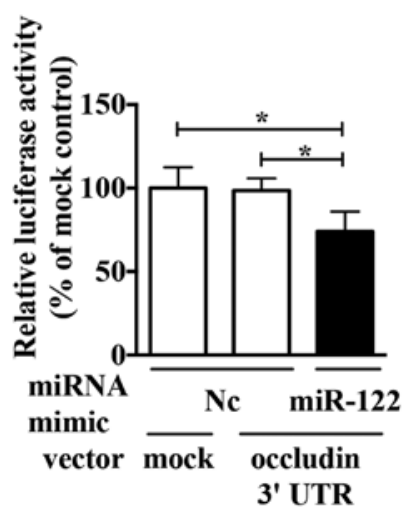

$\mathbf{E}$
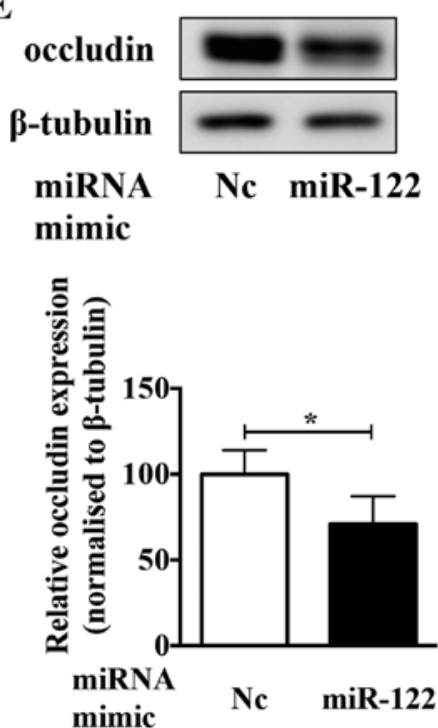

Figure 4. miR-122 targets occludin in ccRCC cells. (A) Predicted miR-122-binding site within the 3'-UTR of the human occludin gene. (B) Caki-2 cells were co-transfected with the luciferase reporter construct containing the predicted miR-122-binding site from the occludin 3'-UTR and miR-122 inhibitor, or the negative control miRNA inhibitor. Values are mean \pm SD of three independent experiments. ${ }^{* *}$ p $<0.01$ vs. each control. (C) ACHN cells were co-transfected with the luciferase reporter construct containing the predicted miR-122-binding site within the occludin 3 '-UTR and miR-122 mimic, or the negative control miRNA mimic. Values are mean \pm SD of four independent experiments. * $p<0.05$ vs. each control. (D) Caki- 2 cells were transfected with the control and miR-122 inhibitors for $72 \mathrm{~h}$, and then protein samples were collected and subjected to western blot analysis with anti-occludin antibody. The membrane was re-probed with the anti- $\beta$-tubulin antibody. Relative occludin expression is shown as mean \pm SD of six independent experiments. ${ }^{* *}$ p $<0.01$ vs. the control inhibitor. (E) ACHN cells were transfected with the control and miR-122 mimics for $72 \mathrm{~h}$, then protein samples were collected and subjected to western blot analysis with an anti-occludin antibody. The membrane was re-probed with the anti- $\beta$-tubulin antibody. Relative occludin expression is shown as mean \pm SD of four independent experiments. ${ }^{\mathrm{p}} \mathrm{p}<0.05$ vs. the control mimic.

surface in Caki-2 cells (Fig. 5E). To examine whether miR-122 expression and occludin protein expression are negatively correlated, immunohistochemistry analysis was performed on the ccRCC samples with the lowest and highest miR122-expression (10 samples for each). ccRCC tissues with high levels of miR-122 expression had a significantly weak occludin quick score compared to those with low levels of miR-122 expression (Fig. 5F and G). Moreover, miR-122 and occludin protein expression showed a negative correlation in the ccRCC tissues (Fig. 5H).

miR-122 promotes MAPK signaling in ccRCC cell lines. Although the miR-122 mimic upregulated the cell proliferation, motility, and invasion activities, occludin knockdown only upregulated cell motility. Target prediction programs predict that putative miR-122 binding sequences exist in other genes involved in cell growth [e.g., p27 (36), PHD3 $(37,38)$, and DUSP2 (39)] and invasion [e.g., CPEB1 (40), FOXP2 (41), and $S O X 17$ (42)]. Occludin is known to mediate the MAPK signalling pathway via oncogenic proteins such as Raf (29). Therefore, we examined the effect of miR-122 on the MAPK pathway by miR-122 overexpression and loss of function experiments. We found that miR-122 affected the phosphorylation status of Erk1/2 and p38 (Fig. 6A). Likewise, occludin knockdown upregulated the phosphorylation status of Erk1/2 (Fig. 6B). Therefore, miR-122 might also mediate ccRCC cell growth and invasion via occludin and other target molecules including MAPK signalling components. 
A

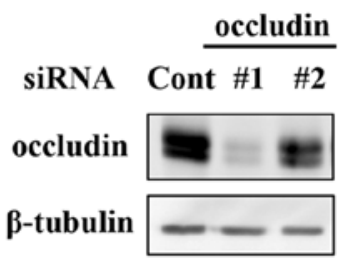

D

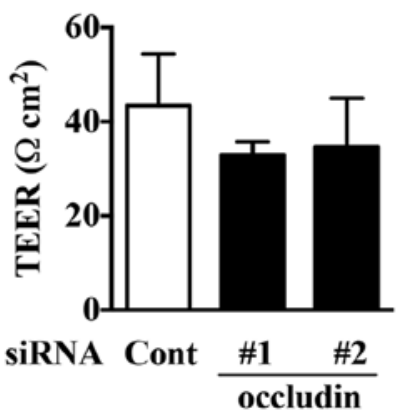

B

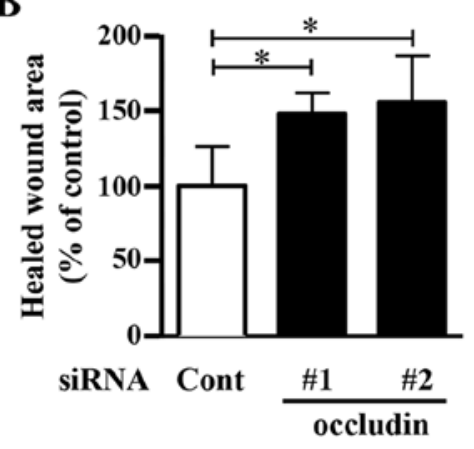

E

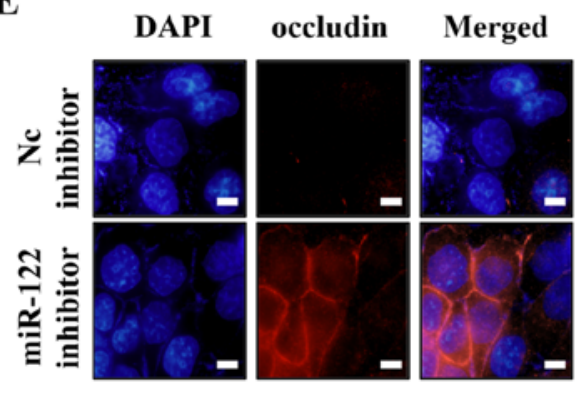

C

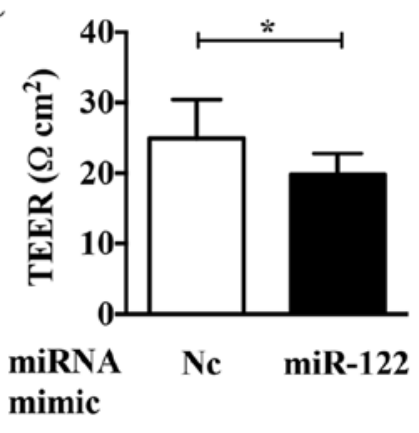

F

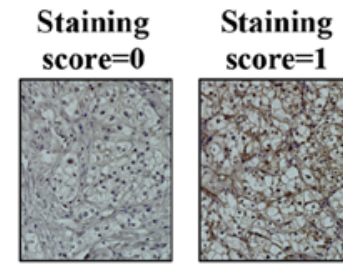

Staining

score $=2$

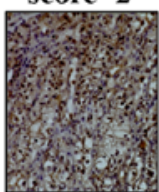

Staining

score $=3$

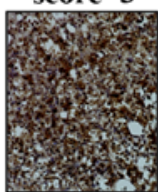

G

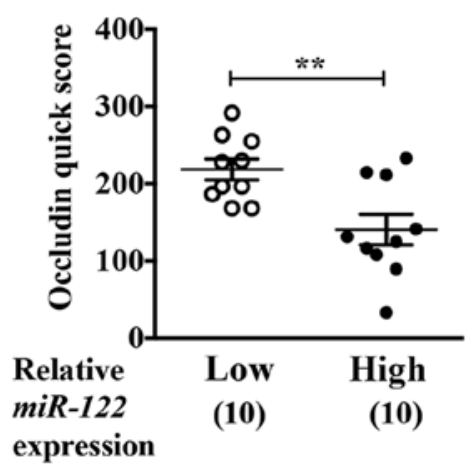

H

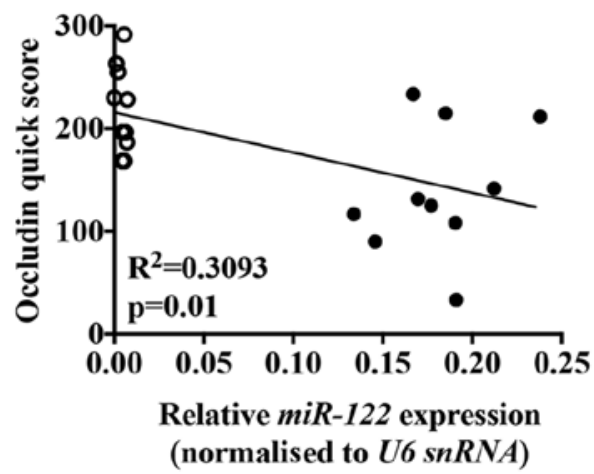

Figure 5. miR-122 expression correlates with occludin protein expression in ccRCC specimens. (A) ACHN cells were transfected with the occludin siRNAs for $72 \mathrm{~h}$, and then protein samples were collected and subjected to western blot analysis with anti-occludin antibody. The membrane was re-probed with the anti- $\beta$-tubulin antibody. Representative results of three independent experiments are shown. (B) Cell migration was measured $12 \mathrm{~h}$ after a wound was created by scraping. Representative results of cell mobility in the scratch wound-healing assay are shown. The results are expressed as means \pm SD of four independent experiments. ${ }^{*}$ p $<0.05$ vs. the control siRNA. ACHN cells were transfected with the miR-122 mimic (C) and two kinds of occludin siRNAs (D) for $48 \mathrm{~h}$, and TEER analysis was performed. Values are mean \pm SD of four independent experiments for (C) and three independent experiments for (D). (E) Caki-2 cells were transfected with the miR-122 inhibitor for $72 \mathrm{~h}$ and then immunofluorescence staining was performed with the anti-occludin antibody and 4',6-diamidino2-phenylindole (DAPI). Representative images of three independent experiments are shown. White bars indicate $10 \mu \mathrm{m}$. The expression of occludin in ccRCC specimens was examined by immunohistochemical staining. Occludin expression was classified into four groups by staining score (F). ccRCC tissue samples with the lowest and highest levels of miR-122 expression were examined (10 of each). ${ }^{* *}$ p<0.01 vs. the lower miR-122-expressed ccRCC (G). (H) Correlation analysis was performed between the occludin quick score and the relative miR-122 expression. $\mathrm{R}^{2}=0.3093, \mathrm{p}=0.01$.

\section{Discussion}

In the present study, we found that high expression of miR-122 was significantly correlated with poor progressionfree survival in ccRCC. Overexpression and loss of function experiments revealed that miR-122 functions as an oncomiR by upregulating malignant phenotypes in ccRCC cells. We identified that miR-122 directly targets occludin in ccRCC cells. Moreover, we showed that the miR-122 expression levels and occludin protein levels are negatively correlated in ccRCC clinical specimens.

Although miR-122 mimic significantly downregulated the TEER in ACHN cells, occludin knockdown only slightly suppressed the TEER (Fig. 5D). Claudin1 and PVRL1, which 
A

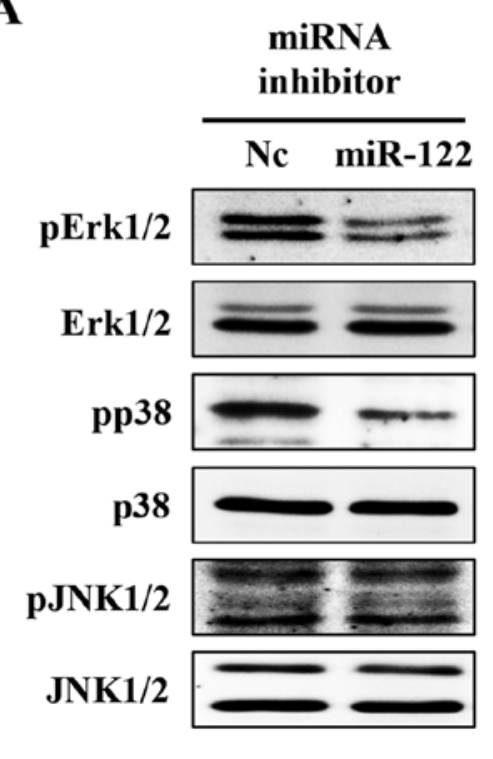

miRNA mimic

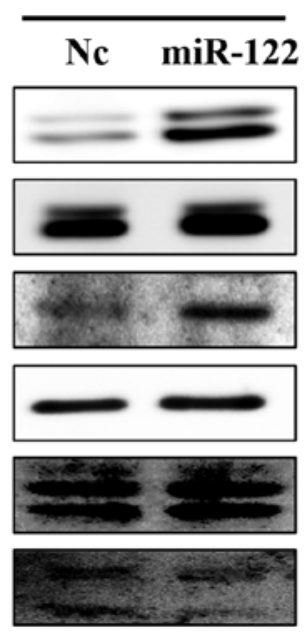

B

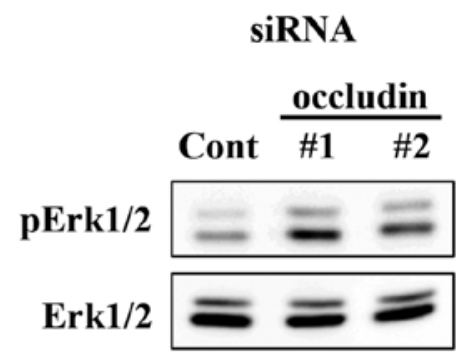

Figure 6. The effect of miR-122 on MAPKs activation in ccRCC cells. Caki-2 cells were transfected with the miR-122 inhibitor (A, left), and ACHN cells were transfected with miR-122 mimic (A, right) or the occludin siRNAs (B) for $72 \mathrm{~h}$. Protein samples were collected and subjected to western blot analysis with anti-phospho Erk1/2 $\left(\mathrm{Thr}^{202} / \mathrm{Tyr}^{204}\right)$, anti-Erk1/2, anti-phospho $\mathrm{p} 38\left(\mathrm{Thr}^{180} / \mathrm{Tyr}^{182}\right)$, anti-p38, anti-phospho JNK1/2 (Thr $\left.{ }^{183} / \mathrm{Tyr}^{185}\right)$, and anti-JNK1/2 antibodies Representative results of three independent experiments are shown.

play roles in the organization of adherence junctions and tight junctions $(43,44)$, respectively, also have potential miR-122 binding sites within their 3'UTRs. Therefore, miR-122 might upregulate cell motility of these proteins as well as occludin in ccRCC cells.

Although miR-122 expression was not correlated with pathological stages and grades, miR-122 expression was significantly high in ccRCC tissues accompanied by lymphatic invasion compared with those without lymphatic invasion (Fig. 1E). Lymphovascular invasion correlates with adverse outcome in several malignancies (45-47). In ccRCC, lymphovascular invasion is associated with metastasis-free survival, disease-specific survival, and overall survival $(48,49)$. While the precise mechanism needs to be investigated further, high miR-122 expression might lead to increased lymphovascular invasion via upregulated cell motility and invasion activities, leading to a poorer prognosis for ccRCC patients.

Originally miR-122 was reported as a tumour suppressor gene in hepatocellular carcinoma (HCC) (12-14). However, in breast cancer, miR-122 has been reported as a tumour suppressor targeting insulin-like growth factor 1 receptor (IGF1R) (50), and as an oncomiR by reprogramming the glucose metabolism in the tumour microenvironment via the exosome (18). The present study demonstrates for the first time that, unlike that in HCC or breast cancer, miR-122 functions as an oncomiR in ccRCC in both cell lines and clinical specimens. Lian et al showed that miR-122 expression led to upregulated cancer cell malignancy phenotypes in RCC (17), consistent with our present study in ccRCC. The phase II clinical study of miR-122-targeted locked nucleic acid (LNA), miravirsen, inhibits viral proliferation, resulting in a long-lasting antiviral effect against $\mathrm{HCV}$ without evidence of viral resistance (51). Therefore, a miR-122-targeted bridged nucleic acid might be a promising molecular-targeted drug for the treatment of ccRCC.

\section{Acknowledgements}

This study was supported by a Grant-in-Aid for Scientific Research (25670025) from the Ministry of Education, Culture, Sports, Science and Technology of Japan and by Project MEET, Osaka University Graduate School of Medicine. The TEER measurement with the Millicell ${ }^{\circledR}$ ERS-2 voltohmmeter was kindly supported by Dr Takefumi Doi and Dr Yoshiaki Okada (Graduate School of Pharmaceutical Sciences, Osaka University). N. Nonomura received commercial research grants from Takeda Pharmaceutical, Novartis Pharma, and Astra Zeneca.

\section{References}

1. Jonasch E, Futreal PA, Davis IJ, Bailey ST, Kim WY, Brugarolas J, Giaccia AJ, Kurban G, Pause A, Frydman J, et al: State of the science: An update on renal cell carcinoma. Mol Cancer Res 10: 859-880, 2012.

2. Dutcher JP: Recent developments in the treatment of renal cell carcinoma. Ther Adv Urol 5: 338-353, 2013.

3. Ha M and Kim VN: Regulation of microRNA biogenesis. Nat Rev Mol Cell Biol 15: 509-524, 2014.

4. Jansson MD and Lund AH: MicroRNA and cancer. Mol Oncol 6: 590-610, 2012.

5. Lin S and Gregory RI: MicroRNA biogenesis pathways in cancer. Nat Rev Cancer 15: 321-333, 2015.

6. Li M, Wang Y, Song Y, Bu R, Yin B, Fei X, Guo Q and Wu B: MicroRNAs in renal cell carcinoma: A systematic review of clinical implications (Review). Oncol Rep 33: 1571-1578, 2015.

7. Weng L, Wu X, Gao H, Mu B, Li X, Wang JH, Guo C, Jin JM, Chen Z, Covarrubias M, et al: MicroRNA profiling of clear cell renal cell carcinoma by whole-genome small RNA deep sequencing of paired frozen and formalin-fixed, paraffinembedded tissue specimens. J Pathol 222: 41-51, 2010.

8. Jingushi K, Ueda Y, Kitae K, Hase H, Egawa H, Ohshio I, Kawakami R, Kashiwagi Y, Tsukada Y, Kobayashi T, et al: miR-629 targets TRIM33 to promote TGF $\beta /$ Smad signaling and metastatic phenotypes in ccRCC. Mol Cancer Res 13: 565-574, 2015.

9. Nakata W, Uemura M, Sato M, Fujita K, Jingushi K, Ueda Y, Kitae K, Tsujikawa K and Nonomura N: Expression of miR$27 \mathrm{a}-3 \mathrm{p}$ is an independent predictive factor for recurrence in clear cell renal cell carcinoma. Oncotarget 6: 21645-21654, 2015. 
10. Osanto S, Qin Y, Buermans HP, Berkers J, Lerut E, Goeman JJ and van Poppel H: Genome-wide microRNA expression analysis of clear cell renal cell carcinoma by next generation deep sequencing. PLoS One 7: e38298, 2012.

11. Tang K and Xu H: Prognostic value of meta-signature miRNAs in renal cell carcinoma: An integrated miRNA expression profiling analysis. Sci Rep 5: 10272, 2015

12. Gramantieri L, Ferracin M, Fornari F, Veronese A, Sabbioni S Liu CG, Calin GA, Giovannini C, Ferrazzi E, Grazi GL, et al: Cyclin G1 is a target of miR-122a, a microRNA frequently downregulated in human hepatocellular carcinoma. Cancer Res 67: 6092-6099, 2007.

13. Yang F, Zhang L, Wang F, Wang Y, Huo XS, Yin YX, Wang YQ, Zhang $\mathrm{L}$ and Sun SH: Modulation of the unfolded protein response is the core of microRNA-122-involved sensitivity to chemotherapy in hepatocellular carcinoma. Neoplasia 13 590-600, 2011.

14. Nassirpour R, Mehta PP and Yin MJ: miR-122 regulates tumorigenesis in hepatocellular carcinoma by targeting AKT3. PLoS One 8: e79655, 2013.

15. Chow TF, Youssef YM, Lianidou E, Romaschin AD, Honey RJ, Stewart R, Pace KT and Yousef GM: Differential expression profiling of microRNAs and their potential involvement in renal cell carcinoma pathogenesis. Clin Biochem 43: 150-158, 2010.

16. Chen J, Zhang D, Zhang W, Tang Y, Yan W, Guo L and Shen B: Clear cell renal cell carcinoma associated microRNA expression signatures identified by an integrated bioinformatics analysis. J Transl Med 11: 169, 2013.

17. Lian JH, Wang WH, Wang JQ, Zhang $\mathrm{YH}$ and $\mathrm{Li} \mathrm{Y}$ MicroRNA-122 promotes proliferation, invasion and migration of renal cell carcinoma cells through the PI3K/Akt signaling pathway. Asian Pac J Cancer Prev 14: 5017-5021, 2013.

18. Fong MY, Zhou W, Liu L, Alontaga AY, Chandra M, Ashby J, Chow A, O'Connor ST, Li S, Chin AR, et al: Breastcancer-secreted miR-122 reprograms glucose metabolism in premetastatic niche to promote metastasis. Nat Cell Biol 17: 183-194, 2015

19. Tsukita S and Furuse M: Occludin and claudins in tight-junction strands: Leading or supporting players? Trends Cell Biol 9: 268-273, 1999.

20. Jiang WG, Martin TA, Matsumoto $K$, Nakamura $T$ and Mansel RE: Hepatocyte growth factor/scatter factor decreases the expression of occludin and transendothelial resistance (TER) and increases paracellular permeability in human vascular endothelial cells. J Cell Physiol 181: 319-329, 1999.

21. Jiang WG, Bryce RP, Horrobin DF and Mansel RE: Regulation of tight junction permeability and occludin expression by polyunsaturated fatty acids. Biochem Biophys Res Commun 244: 414-420, 1998.

22. Gopalakrishnan S, Raman N, Atkinson SJ and Marrs JA: Rho GTPase signaling regulates tight junction assembly and protects tight junctions during ATP depletion. Am J Physiol 275 : C798-C809, 1998.

23. van ZF: Krupitza G and Mikulits W: Initial steps of metastasis: Cell invasion and endothelial transmigration. Mutat Res 728 23-34, 2011.

24. Stoletov K, Kato H, Zardouzian E, Kelber J, Yang J, Shattil S and Klemke R: Visualizing extravasation dynamics of metastatic tumor cells. J Cell Sci 123: 2332-2341, 2010.

25. Shin K, Fogg VC and Margolis B: Tight junctions and cell polarity. Annu Rev Cell Dev Biol 22: 207-235, 2006.

26. Rao R: Occludin phosphorylation in regulation of epithelial tight junctions. Ann NY Acad Sci 1165: 62-68, 2009.

27. Van Itallie CM, Fanning AS, Holmes J and Anderson JM: Occludin is required for cytokine-induced regulation of tight junction barriers. J Cell Sci 123: 2844-2852, 2010.

28. Raleigh DR, Boe DM, Yu D, Weber CR, Marchiando AM Bradford EM, Wang Y, Wu L, Schneeberger EE, Shen L, et al: Occludin S408 phosphorylation regulates tight junction protein interactions and barrier function. J Cell Biol 193: 565-582, 2011.

29. Li D and Mrsny RJ: Oncogenic Raf-1 disrupts epithelial tight junctions via downregulation of occludin. J Cell Biol 148: 791-800, 2000

30. Runkle EA, Rice SJ, Qi J, Masser D, Antonetti DA, Winslow MM and $\mathrm{Mu} \mathrm{D}$ : Occludin is a direct target of thyroid transcription factor-1 (TTF-1/NKX2-1). J Biol Chem 287: 28790-28801, 2012

31. Osanai M, Murata M, Nishikiori N, Chiba H, Kojima T and Sawada N: Epigenetic silencing of occludin promotes tumorigenic and metastatic properties of cancer cells via modulations of unique sets of apoptosis-associated genes. Cancer Res 66: 9125-9133, 2006.
32. Osanai M, Murata M, Nishikiori N, Chiba H, Kojima T and Sawada N: Occludin-mediated premature senescence is a fail-safe mechanism against tumorigenesis in breast carcinoma cells. Cancer Sci 98: 1027-1034, 2007.

33. Long H, Crean CD, Lee WH, Cummings OW and Gabig TG Expression of Clostridium perfringens enterotoxin receptors claudin-3 and claudin-4 in prostate cancer epithelium. Cancer Res 61: 7878-7881, 2001.

34. Tzelepi VN, Tsamandas AC, Vlotinou HD, Vagianos CE and Scopa CD: Tight junctions in thyroid carcinogenesis: Diverse expression of claudin-1, claudin-4, claudin-7 and occludin in thyroid neoplasms. Mod Pathol 21: 22-30, 2008.

35. Harten SK, Shukla D, Barod R, Hergovich A, Balda MS, Matter K, Esteban MA and Maxwell PH: Regulation of renal epithelial tight junctions by the von Hippel-Lindau tumor suppressor gene involves occludin and claudin 1 and is independent of E-cadherin. Mol Biol Cell 20: 1089-1101, 2009.

36. Blain SW, Scher HI, Cordon-Cardo C and Koff A: p27 as a target for cancer therapeutics. Cancer Cell 3: 111-115, 2003.

37. Henze AT, Garvalov BK, Seidel S, Cuesta AM, Ritter M Filatova A, Foss F, Dopeso H, Essmann CL, Maxwell PH, et al: Loss of PHD3 allows tumours to overcome hypoxic growth inhibition and sustain proliferation through EGFR. Nat Commun 5: 5582, 2014

38. Garvalov BK, Foss F, Henze AT, Bethani I, Gräf-Höchst S, Singh D, Filatova A, Dopeso H, Seidel S, Damm M, et al: PHD3 regulates EGFR internalization and signalling in tumours. Nat Commun 5: 5577, 2014.

39. Lin SC, Chien CW, Lee JC, Yeh YC, Hsu KF, Lai YY, Lin SC and Tsai SJ: Suppression of dual-specificity phosphatase- 2 by hypoxia increases chemoresistance and malignancy in human cancer cells. J Clin Invest 121: 1905-1916, 2011.

40. Nagaoka K, Fujii K, Zhang H, Usuda K, Watanabe G, Ivshina M and Richter JD: CPEB1 mediates epithelial-to-mesenchyme transition and breast cancer metastasis. Oncogene 35: 2893-2901, 2016.

41. Yan X, Zhou H, Zhang T, Xu P, Zhang S, Huang W, Yang L, $\mathrm{Gu}$ X, Ni R and Zhang T: Downregulation of FOXP2 promoter human hepatocellular carcinoma cell invasion. Tumour Biol 36: 9611-9619, 2015

42. Kuo IY, Wu CC, Chang JM, Huang YL, Lin CH, Yan JJ, Sheu BS, Lu PJ, Chang WL, Lai WW, et al: Low SOX17 expression is a prognostic factor and drives transcriptional dysregulation and esophageal cancer progression. Int J Cancer 135: 563-573, 2014.

43. Günzel D and Yu AS: Claudins and the modulation of tight junction permeability. Physiol Rev 93: 525-569, 2013.

44. Takai $Y$ and Nakanishi H: Nectin and afadin: Novel organizers of intercellular junctions. J Cell Sci 116: 17-27, 2003.

45. Cheng L, Montironi R, Davidson DD and Lopez-Beltran A: Staging and reporting of urothelial carcinoma of the urinary bladder. Mod Pathol 22 (Suppl 2): S70-S95, 2009.

46. Lim SB, Yu CS, Jang SJ, Kim TW, Kim JH and Kim JC: Prognostic significance of lymphovascular invasion in sporadic colorectal cancer. Dis Colon Rectum 53: 377-384, 2010.

47. Cheng L, Jones TD, Lin H, Eble JN, Zeng G, Carr MD and Koch MO: Lymphovascular invasion is an independent prognostic factor in prostatic adenocarcinoma. J Urol 174: 2181-2185, 2005.

48. Katz MD, Serrano MF, Humphrey PA, Grubb RL III, Skolarus TA, Gao F and Kibel AS: The role of lymphovascular space invasion in renal cell carcinoma as a prognostic marker of survival after curative resection. Urol Oncol 29: 738-744, 2011.

49. Belsante M, Darwish O, Youssef R, Bagrodia A, Kapur P, Sagalowsky AI, Lotan Y and Margulis V: Lymphovascular invasion in clear cell renal cell carcinoma - association with disease-free and cancer-specific survival. Urol Oncol 32: 30.e23-30.e28, 2014.

50. Wang B, Wang H and Yang Z: MiR-122 inhibits cell proliferation and tumorigenesis of breast cancer by targeting IGF1R. PLoS One 7: e47053, 2012

51. Janssen HL, Reesink HW, Lawitz EJ, Zeuzem S, RodriguezTorres M, Patel K, van der Meer AJ, Patick AK, Chen A, Zhou Y, et al: Treatment of HCV infection by targeting microRNA. N Engl J Med 368: 1685-1694, 2013. 